\title{
Author Correction: Self-Aggregation of Deep Convection and its Implications for Climate
}

\author{
Allison A. Wing ${ }^{1}$ \\ Published online: 12 July 2019 \\ (C) Springer Nature Switzerland AG 2019
}

\section{Author Correction: Current Climate Change Reports (2019) 5(1):1-11 \\ https://doi.org/10.1007/s40641-019-00120-3}

The original version of this article contained a mistake. In the recently published paper, "Self-Aggregation of Deep Convection and its Implications for Climate", there was an error in Eq. 1, as a "+" was inadvertently dropped before the final portion of the equation. The correct equation is below:

$\lambda=\frac{d R}{d T}=\frac{d N}{d T}+A \frac{d B}{d T}+B \frac{d A}{d T}$

The authors apologize for this oversight and for any confusion it may have caused.

Publisher's Note Springer Nature remains neutral with regard to jurisdictional claims in published maps and institutional affiliations.

The online version of the original article can be found at https://doi.org/ 10.1007/s40641-019-00120-3

\footnotetext{
Allison A. Wing

awing@fsu.edu

1 Department of Earth, Ocean and Atmospheric Science, Florida State University, Tallahassee, FL, USA
} 